\title{
Knowledge Regarding Basic Life Support Among Nurses of a Tertiary Level Hospital of Nepal
}

\author{
Shanti Bajracharya ${ }^{1}$, Liza Nagarkoti ${ }^{1}$
}

${ }^{1}$ College of Nursing, Nepalese Army Institute of Health Sciences, Kathmandu, Nepal.

\section{ABSTRACT}

Introduction: Basic life support (BLS) is an emergency procedure that consists of recognizing an arrest and initiating proper cardio pulmonary resuscitation (CPR) techniques to maintain life until victims either recovers or is transported to medical facility where advanced life support are available. It is very important that all nurses know about basic life support to save lives of patients. Methods: A descriptive cross-sectional study was conducted in 50 nurses working in various intensive and high care units of our teaching hospital to assess their Knowledge on BLS. Non-probability purposive sampling technique was used for data collection for which self-administered semi-structured questionnaire was used. Results: Majority (46\%) of the respondents were between 20 to 25 years of age. $52 \%$ of respondents were of Proficiency Certificate Level (PCL), $36 \%$ of bachelor of nursing (BN) and 12\% Bachelor of Science in Nursing (B.Sc Nursing). 36\% respondents had working experience of 5-10 years and $6 \%$ of $10-15$ years. All respondents had heard about BLS but $86 \%$ of them had never attended any BLS training. Most of the respondents ( $86 \%$ ) had seen CPR being done and more than half of the respondents (58\%) had done CPR. 62\% stated circulation, airway and breathing as the latest CPR sequence. $90 \%$ of the respondents said cardiac arrest is the indication of CPR. $66 \%$ had inadequate knowledge, 32\% had moderate knowledge while minority $2 \%$ had adequate knowledge on Basic Life Support. Conclusion: Knowledge of Basic Life Support (BLS) among Nepalese nurses was inadequate in majority of cases. There was also no association between the knowledge and academic qualification or experience.

Keywords: nursing knowledge; basic life Support; cardiao pulmonary resuscitation

\section{INTRODUCTION}

Basic life support (BLS) is an emergency procedure that consists of recognizing an arrest and initiating proper Cardiac Pulmonary Resuscitation (CPR) techniques to maintain life until victims either recovers or is transported to medical facility where advance life support are available ${ }^{1}$. Resuscitation is the art of restoring life or consciousness of one apparently dead ${ }^{2}$. The most important aspects in BLS are airway, breathing and circulation.
Failure of the circulation for three to four minutes will lead to irreversible cerebral damage. Cardiac arrest is an important acute emergency situation both in/out of the hospital set ups and carries a high level of mortality risk, however if early BLS and cardio

Correspondence: Shanti Bajracharya, College of Nursing, Nepalese Army Institute of Health Sciences,Kathmandu, Nepal. Email: bajrashanti1@gmail.com 
pulmonary resuscitation is initiated, the survival rate can be substantially improved. Knowledge of BLS is a major determinant in the success of resuscitation and plays a vital role in the final outcome of acute emergency situations ${ }^{3}$.

Nursing professionals are usually the first to witness a cardiac arrest at the hospital and call for assistance team. Thus, nurses need to have updated technical knowledge and practical skills developed to contribute more efficiently to cardiac arrest maneuvers ${ }^{4}$.

Being important members of the healthcare team, nurses are deemed to possess the basic skills and expertise which are needed to perform CPR. It is documented that a timely performed CPR can largely prevent sudden death and it is hence considered to be an important medical procedure. To perform the procedure in a meticulous manner, nurses should be knowledgeable and they should have expertise in the procedure ${ }^{5,6}$.

Demand for courses of BLS is ever increasing worldwide. However, in developing countries like Nepal, resuscitation training is not routine. Few reports have addressed the current level of awareness and knowledge in this area among the health care professionals in Nepal. In recent years, several publications have highlighted the deficiencies in CPR quality, both out-ofhospital and in-hospital, which have partly been addressed in the newest BLS guidelines?

The main aim of the study was to assess the Knowledge regarding Basic Life Support (BLS) among the Nurses of Shree Birendra Hospital.

\section{METHODS}

A descriptive cross Sectional study was done to assess the Knowledge regarding Basic Life
Table 1: Association between Knowledge and Qualification of the Respondents. $p$ value was $>0.001$.

\begin{tabular}{|l|c|c|c|}
\hline Qualification & \multicolumn{3}{|c|}{ Knowledge } \\
\hline & Inadequate & Moderate & Total \\
\hline PCL & $17(65.4 \%)$ & $9(34.6 \%)$ & 26 \\
\hline BN & $11(64.7 \%)$ & $6(35.3 \%)$ & 17 \\
\hline B Sc & $4(66.7 \%)$ & $2(33.3 \%)$ & 6 \\
\hline Total & $32(65.3 \%)$ & $17(34.7 \%)$ & 49 \\
\hline
\end{tabular}

Table 2: Association between Knowledge and work experience of the Respondents. $p$ value was $>0.001$.

\begin{tabular}{|l|c|c|c|}
\hline $\begin{array}{l}\text { Experience } \\
\text { (in years) }\end{array}$ & \multicolumn{3}{|c|}{ Knowledge } \\
\hline & Inadequate & Moderate & Total \\
\hline $1-3$ years & $9(52.9 \%)$ & $8(47.1 \%)$ & 17 \\
\hline 3-6 years & $14(82.4 \%)$ & $3(17.6 \%)$ & 17 \\
\hline $6-9$ years & $2(66.7 \%)$ & $1(33.3 \%)$ & 3 \\
\hline$>9$ years & $7(58.3 \%)$ & $5(41.7 \%)$ & 12 \\
\hline Total & $32(65.3 \%)$ & $17(34.7 \%)$ & 49 \\
\hline
\end{tabular}

Support among the Nurses our teaching hospital. Non-probability purposive sampling technique was used for data collection for which self-administered semi-structured questionnaire was used. Total participants were 50 nurses working in critical and high care units (ICU / CCU, ITCU, OT, HCU, ER).

\section{RESULTS}

$52 \%$ of participants were of certificate level, 36 $\%$ of Bachelor in Nursing and $12 \%$ B. Sc Nursing. $36 \%$ of them had working experience of 5 to 10 years $6 \%$ had working experience of $10-15$ years. $30 \%$ were currently working in ICU / CCU, $28 \%$ in OT, $16 \%$ in ITCU, $14 \%$ in ER and $12 \%$ in HCU. All of them had heard about BLS, $36 \%$ from hospital $2 \%$ from 


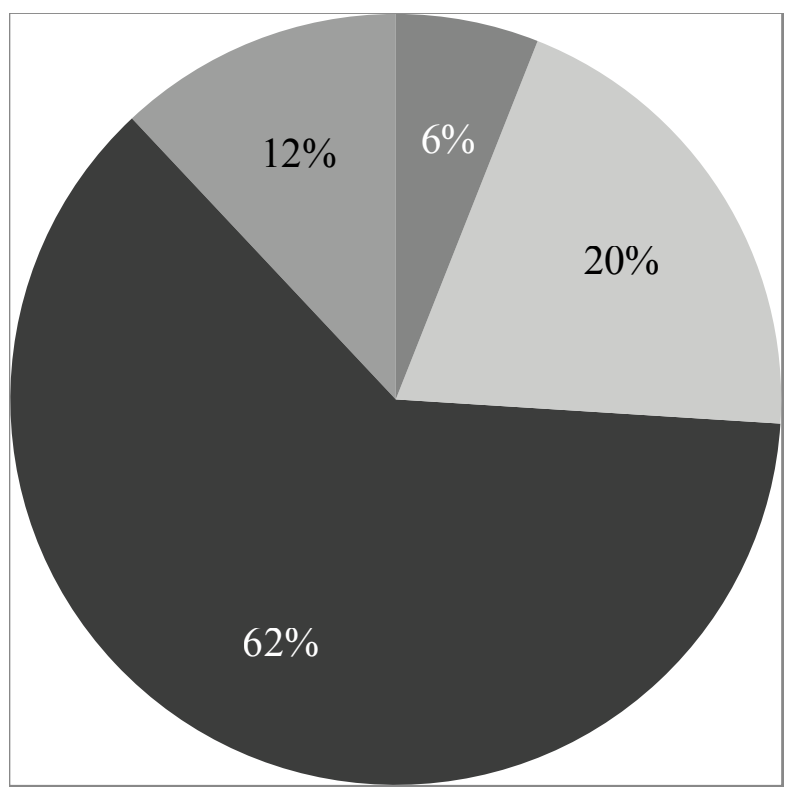

Circulation, airway, breathing Circulation, breathing, airway Breathing circulation, airway Breathing, airway, circulation

Figure 1: Knowledge regarding latest CPR sequence

internet and others had heard from other sources.

$58 \%$ had done CPR on a patient. $62 \%$ said that consciousness is confirmed by shaking the victims and shouting "Are you OK?," 66\% said carotid pulse to be palpated to assess the circulation and $72 \%$ of the respondents answered cardiac compression are initiated if carotid pulse is not palpable for 5-10 seconds. $68 \%$ of the respondents said 'pinch nostrils, take a deep breath and blow into victim's mouth' to initiate artificial breathing whereas only $2 \%$ of the respondents said 'blow into victim's mouth like blowing up a balloon'. 56\% answered 1 breath is delivered every 5 seconds to continue mouth to mouth breathing, if the victim does not resume breathing and 90\% respondents said cardiac arrest as the indication of CPR; only $10 \%$ of the respondents said respiratory arrest. $94 \%$ of the respondents answered 'in supine position on a firm flat surface' as the position of patient during resuscitation, $50 \%$ of the respondents said xiphisternum is location for chest compressions, $40 \%$ said mid chest, $6 \%$ said left side of chest and $4 \%$ said right side of the chest should be compressed. $64 \%$ said $30: 2$ as the ratio of CPR, only $4 \%$ of the respondents said $30: 1$.

$78 \%$ of the respondents said 'heel of one hand on the sternum and heel of other hand on the top of it interlocking the fingers' is done when performing external cardiac compressions, $4 \%$ of the respondents said the finger of one hand on the sternum and finger of other hand on the top of them and $80 \%$ said that carotid pulse is checked after 4 cycles of CPR. 68\% said carotid pulse and $6 \%$ said radial pulse should be checked to assess the success of CPR. The sequence of CPR as said by participants is shown in figure 1 .

Two thirds of participants had inadequate knowledge, $32 \%$ had moderate knowledge and only $2 \%$ had adequate knowledge about BLS.

\section{DISCUSSION}

Majority $62 \%$ of the respondents stated circulation, airway and breathing as the latest CPR sequence which was in contrast with the study conducted by Sharma \& Attar $7,{ }^{8}$. Nearly half i.e. $40 \%$ of the respondents said that start $\mathrm{CPR}$ as an immediate action if somebody is not responding while only $4 \%$ of the respondents said to observe and $20 \%$ of the respondents answered to keep him in the recovery (sideline) position. Regarding correct maneuver to clear airway, $76 \%$ of the respondents said head tilt, chin lift or jaw thrust which was consistent with the study done by Parajulee \& Selvaraj 5 . $82 \%$ of the respondents said that the number of compressions done in $1 \mathrm{~min}$ is 100 which was 
contradicting the study done by Parajulee \& Selvaraj ${ }^{5}$. Regarding depth of compression $66 \%$ of the respondents said that the depth of compression during CPR is 1.5-2 inches which was similar with the study of Sharma $\&$ Attar $^{8}$ but was opposed with the study done by Shekhawat \& Chauhan ${ }^{2}$, Parajulee \& Selvaraj $^{5}$,Chew, et. al., ${ }^{9}$. $52 \%$ of the respondents said $30: 2$ as the ratio of CPR, single rescuer which was inconsistent with the study done by Shekhwat \& Chauhan ${ }^{2}$, and Parajulee \& Selvaraj ${ }^{5}$, whereas only $2 \%$ of the respondents said 30:1. 96\% said rib fracture as the complication of CPR which was opposed with the study done by Parajulee \& Selvaraj ${ }^{5}$.

No statistically significant $(\mathrm{P}<0.001)$ association was found between knowledge of BLS with educational qualification and work experience (Table $1 \& 2$ ).

\section{CONCLUSION}

Most of the nurses working in high care units of our teaching hospital didn't have adequate knowledge about BLS and CPR. Only 2\% had adequate knowledge about BLS. There was no association between the knowledge and academic qualification or work experience.

\section{REFERENCES}

1. Phipps, W.J., Medical Surgical Nursing:Health and illness prospectives. 2003: Mosby

2. Shekhawat, K., \& Chauhan, A. Available on: (2014) Knowledge of Basic Life Support among the Interns and Postgraduate Students of Dental Colleges in Banglore City, Karnataka International Journal of Health Sciences and Research Volume, 158-166

3. Reddy, S., et al., Awareness of Basic Life Support among the staff and students in a
Dental School. Journal of Contemporary Dental Practice, 2013. 14(3): p. 511-517. h t t p ://dx.doi.org/ $10.5005 /$ j p journals-10024-1353

4. Lima, S.G., et al., Permanent education in BLS and ACLS: Impact on the knowledge of nursing professionals. Arquivos Brasileiros de Cardiologia 2009. 93(6).

5. Parajulee, S. and V. Selvaraj, Knowledge of Nurses Towards Cardio-pulmonary Resuscitation in a Tertiary Care Teaching Hospital in Nepal. Journal of Clinical and Diagnostic Research, 2011. 5(8): p. 1585-1588.

6. Choi, H.S., et al., Peer-assisted learning to train high-school students to perform basic life support. World Journal of Emergncy Medicine, 2015. 6(3): p. 186-190. http:// d x . d o i.org / 10.5847 / w j e m.j. 1920-8642.2015.03.004

7. Shrestha, R., et al., Basic life support:knowledge and attitude of medical/ paramedical professionals. World Journal of Emergency Medicine, 2012. 3(4): p. 141-145.

8. Sharma,R \& Attar, N. R.,Adult Basic Life Support (BLS) awareness and knowledge among medical and dental interns completing internship from Deemed University. Nitte University Journal of Health Science,20122(3),6-13.

9. Chew,K.,et al., A survey on Knowledge, Attitude and Confidence level of Adult Cardiopulmonary Resuscitation among junior doctors. Medical Journal of Malaysia, 201166 (1),56-59. 